\title{
Pricing Carbon emissions for Japan based on energy production
}

\author{
$\underline{\text { C.-L. Chang }}{ }^{\text {a }}$, Shigeyuki Hamori ${ }^{\mathrm{b}}$ and M. McAleer ${ }^{\mathrm{c}, \mathrm{d}, \mathrm{e}, \mathrm{f}, \mathrm{g}}$ \\ a Department of Applied Economics and Department of Finance, National Chung Hsing University, \\ Taiwan, \\ ${ }^{b}$ Graduate School of Economics, Kobe University, Kobe, Japan \\ ${ }^{c}$ Department of Finance, Asia University, Taiwan \\ ${ }^{d}$ Discipline of Business Analytics, University of Sydney Business School, Australia \\ ${ }^{e}$ Erasmus School of Economics, Erasmus University Rotterdam, The Netherlands, \\ ${ }^{f}$ Department of Quantitative Economics, Complutense University of Madrid, Spain \\ ${ }^{g}$ Institute of Advanced Sciences, Yokohama National University, Japan \\ Email: changchialin@email.nchu.edu.tw
}

\begin{abstract}
Fossil fuels such as coal, oil and gas generate carbon emissions that contribute to global warming and climate change. Taxes on carbon emissions can mitigate their effects on the environment by changing demand and supply. For taxes to be effective, accurate carbon emissions prices are required. The paper uses an innovative KLEM production function approach to calculate carbon emissions prices for Japan, where carbon emissions are the output, and capital (K), labour (L), energy (E) (or electricity), and materials (M), are the inputs. The variables capital, labour and materials are essentially fixed on a daily, weekly or monthly basis, whereas energy can be changed more frequently, such as daily, weekly or monthly, so that changes in carbon emissions essentially depend on changes in energy. If prices are set according to average cost pricing, the prices of carbon emissions and energy may be approximated by an energy production model with a constant factor of proportionality, so that carbon emissions prices will depend on energy prices. Using this innovative approach, the paper estimates carbon emissions prices for Japan using seasonally adjusted and unadjusted monthly data on the volumes of carbon emissions and energy, and energy prices, from December 2008 to April 2018.
\end{abstract}

Keywords: Fossil fuels, energy, carbon emissions, taxes, KLEM production function 


\section{INTRODUCTION}

The burning of fossil fuels such as coal, oil and gas generate carbon emissions that contribute significantly to global warming and climate change. Taxes on carbon emissions can mitigate the effects of carbon emissions by changing the demand and supply of carbon emissions. For taxes to be effective, accurate prices are required for carbon emissions, but such price data are notoriously difficult to obtain.

The purpose of the paper is to use a novel production function approach to calculate carbon emission prices, where carbon emissions (CE) are the outputs and capital (K), labour (L), energy (E) (that is, electricity), and materials (M), are the inputs into the production function. The variables K, L and M are essentially fixed on a daily, weekly or monthly basis, whereas E can be changed far more frequently, such as daily, weekly or monthly, so that changes in CE essentially depend on changes in E.

If prices are assumed to be set according to average cost pricing, the prices of $\mathrm{CE}$ and $\mathrm{E}$ may be approximated by a model with a constant factor of proportionality. In this setting, the prices of CE depend on the prices of E. Using this novel approach, the paper estimates carbon emissions prices for Japan using seasonally adjusted and unadjusted monthly data on the volumes of carbon emissions and electricity, and the price of electricity, from December 2008 to April 2018. The methodological approach and empirical analysis are entirely new to Japan, and complement the few existing analyses of carbon emissions pricing internationally.

The estimated monthly carbon emissions prices for Japan lie in the range $(1500,5500)$ in all cases considered, including seasonally adjusted and unadjusted data, and accommodating deterministic seasonal patterns in the monthly data. The calculated carbon emissions prices are sensitive and important for public policy consideration. Prices are essential for purposes of imposing taxes on carbon emissions in order to mitigate the effect of carbon emissions on the environment, namely global warming and climate change. An exhaustive search of the literature would seem to suggest that there would seem to be no published theoretical or practical academic literature on pricing carbon emissions for Japan. It is hoped that the innovative theoretical approach and novel empirical results of the paper will encourage further research into pricing carbon emissions, preferably using high frequency time intervals, such as daily data, and to encourage public policy considerations at the international level.

\section{LITERATURE REVIEW}

The literature on pricing carbon emissions is relatively sparse, with most of the research concentrating on China's developing national carbon emissions market. However, as China's carbon market was established only recently in 2013, and has been organised primarily at the domestic regional level, and not necessarily based on competitive market principles, there has been little research on analyzing China's carbon emissions prices and associated volatility. An exception is the recent work of Chang et al. (2019), who establish national carbon emission prices for China

Although the research on China's emerging regional and national carbon emissions trading schemes remains at a developing stage, several useful contributions have been made for purposes of understanding some recent aspects of carbon pricing in China. Among others, Chen (2005) evaluated the costs of mitigating carbon emissions in China. Gregg et al. (2008) analysed the emissions patterns of China as the world leader in carbon 
emissions from fossil fuel consumption and cement production. Daskalakis et al. (2009) provided evidence from modelling $\mathrm{CO} 2$ emissions allowance prices and derivatives in Europe. Li and Colombier (2009) viewed the managing of carbon emissions in China through building energy efficiency. Chang (2010) examined a multivariate causality test of carbon dioxide emissions, energy consumption and economic growth in China.

More recently, Nam et al. (2014) compared the synergy between pollution and carbon emissions control for China and the USA. Zhang et al. (2014) considered emissions trading in China in terms of progress and future prospects. Tang et al. (2015) evaluated the carbon emissions trading scheme exploration in China using a multi-agent-based model. Zhang (2015) reformulated the low-carbon green growth strategy in China. Xiong et al. (2017) compared the allowance mechanism of China's carbon trading pilots with alternative schemes in the EU and California. The research on pricing carbon emissions at an international level is even more limited in coverage, especially using modern statistical and econometric methods. Chang et al. (2017) and Chang and McAleer (2018) use daily data for EU carbon emissions futures prices, US carbon emissions spot prices, and spot and futures prices of oil and coal, to analyze volatility spillovers and Granger causality. Chang, Mai and McAleer (2019) use a novel approach to establish the first set of national carbon emission prices for China.

\section{KLEM PRODUCTION FUNCTION FOR CARBON EMISSIONS AND ENERGY}

A production function relates inputs of goods and services that are used to produce a specific output of a commodity. There are several alternative production functions with different mathematical conditions and associated regularity conditions for statistical modelling. A relatively broad specification is the so-called KLEMS production function (OECD, 2001), which uses Capital (K), Labour (L), Energy (E), Materials (M), and Services (S) as the inputs into the production process. Typically the most widely observable input is energy, which is essentially based on the use of electricity. As a special case of KLEMS, consider the KLEM production function (see, for example, Lecca at al. (2011)) that is given as:

$$
C E=A K^{a 1} L^{a 2} E^{a 3} M^{a 4} \exp (u)
$$

where CE denotes the production of the output of Carbon Emissions, Capital $(K)$, Labour $(L)$, Energy or Electricity $(E)$, and Materials $(M)$ are the inputs into the production process, $A$ is a constant, the partial production parameters are assumed to satisfy constant returns to scale, that is, $a 1+a 2+a 3+a 4=1$ (as in the Cobb-Douglas production function), and the random error term is assumed to be $u \sim i i d(0,1)$. CE are taken as the volume of carbon emissions, as provided by the Japan Meteorological Agency.

In practice, the output of $C E$ and input of $E$ may be observed at a high frequency, such as daily, weekly or monthly, whereas the inputs of $K, L$ and $M$ are generally fixed for long periods of time, such as one year. Consequently, $C E$ and $E$ may be assumed to be proportional, with the random factor of proportionality given by:

$$
k=A K^{a 1} L^{a 2} M^{a 4} \exp (u)
$$

It is worth noting that $k$ does not need to lie in a specified range, such as $(0,1)$. As $k$ has a unit of measurement, $k$ can take any value depending on the units of measure of the variables, such as: 


$$
C E=k E^{a 3}
$$

or

$$
\log (C E)=\log (k)+\mathrm{a} 3 \log (E) .
$$

Under the assumption that output prices are set according to an average cost pricing rule, the prices of $C E$ and $E$ may be approximated by a model with a constant factor of proportionality. Let this relationship be given as:

$$
P_{C E}=k P_{E}
$$

where $P_{C E}$ is the price of $C E, P_{E}$ is the price of energy (such as electricity), such that $k$ in equation (4) is now given as the constant factor of proportionality.

From equation (4), it follows that:

$$
k=C E / E^{a 3} .
$$

where the unit of measurement of $C E$ is $\mathrm{ppm}$, and the unit of measurement of $E^{a 3}$ is $(k W h)^{\mathrm{a} 3}$. Therefore, the unit of measurement of $k$ is $\mathrm{ppm} /\left\{(\mathrm{kWh})^{\mathrm{a} 3}\right\}$, and the unit of measurement of $\mathrm{P}_{\mathrm{E}}$ is $\mathrm{JPY} / k \mathrm{Wh}$. As $P_{C E}=\hat{k} * P_{E}$, the unit of measurement of $\mathrm{P}_{\mathrm{CE}}$ is JPY $* \mathrm{ppm} /\left\{(\mathrm{kWh})^{(1+a 3)}\right\}$. The estimates of $a 3$ in Table 4 are given as 0.018 in all 4 cases using seasonally unadjusted and adjusted data on carbon emissions and electricity volumes.

\section{Monthly Data and Diagnostic Checks}

The innovative theoretical approach presented in the previous section is relatively straightforward to apply in practical situations, especially where carbon emissions have not yet been calculated at the national level. One of the few attempts at establishing national carbon emission prices is the recent work of Chang et al. (2019) for China. The empirical analysis uses a monthly sample period from December 2008 to April 2018 for Japan, where carbon emission prices have not yet been calculated.

Some previous research on carbon emissions has used the concentration value of carbon dioxide. The purpose of the paper is to price the volume of carbon emissions using an innovative theoretical approach, and a novel empirical analysis based on data provided by the Japan Meteorological Agency and the Japan Electricity Power eXchange.

\section{EMPIRICAL ESTIMATES AND ANALYSIS}

The results of the ADF unit root tests and Johansen tests of the number of cointegrating vectors in the previous section leads to the estimation of cointegrating vectors. For this purpose, we use the Fully-Modified OLS estimation (see Phillips and Hansen (1990)) of the cointegrating regressions in Table 4.

Four cases are considered, as follows:

Case 1: Seasonally adjusted data;

Case 2: Seasonally unadjusted data with no seasonal dummy variables; 
Case 3: Seasonally unadjusted data with 4 seasonal dummy variables;

Case 4: Seasonally unadjusted data with 12 seasonal dummy variables

It is not clear whether seasonally unadjusted or seasonally adjusted data will lead to more accurate estimates of carbon emissions prices, so both will be used and compared. It is worth highlighting that the logarithm of seasonally adjusted electricity volume is statistically significant in explaining the logarithm of seasonally adjusted carbon emissions volume (Case 1). A very similar set of estimates is obtained in case 2 , where the logarithm of seasonally unadjusted electricity volume is statistically significant in explaining the logarithm of seasonally unadjusted carbon emissions volume, in the absence of any seasonal dummy variables. The Adjusted R-squared values (reported as Adjusted $\mathrm{R}^{2}$ ) cannot be strictly compared as the dependent variables are different.

Case 2 is augmented with the use of 4 seasonal monthly dummy variables in Case 3, and 11 seasonal monthly dummy variables in Case 4. In both cases, only the July, August, September and October monthly seasonal dummy variables are statistically significant. The Adjusted R-squared values for cases 1, 3 and 4 are very similar, at $0.894,0.877$ and 0.904 , respectively.

It is worth noting that the effects of the logarithm of seasonally unadjusted electricity volume are statistically significant in explaining the logarithm of seasonally unadjusted carbon emissions volume, with the estimated effects being identical at 0.018 in each case. This is essential in estimating $k$ accurately to calculate carbon emission prices based on electricity prices.

This leads to calculating the correlations of the estimated prices of carbon emissions in each case, for both seasonally adjusted and seasonally unadjusted data. As $P_{C E}=k P_{E}, \hat{k}$ is used to calculate $P_{C E}=\hat{k} P_{E}$ (denoted $\mathrm{P}_{\mathrm{CE}}=\hat{k} \mathrm{P}_{\mathrm{E}}$ in Figures $1-4$ ). The correlations of the calculated carbon emissions prices in Table 5 using cases 1-4 are extremely high. Given the relationship between carbon emission prices and electricity prices has been established as $P_{C E}=\hat{k} P_{E}$, if there are similar values for $\hat{k}$ in any two cases, then it is possible that the correlations will be unity or very close to unity in these cases.

As $\hat{k}=274.309$ in Case 1 and $\hat{k}=274.083$ in Case 2 , the extremely high correlations in the range $(0.9996$, 1) are not especially surprising for these cases. For reasons given previously, the correlations of the seasonally adjusted prices in Case 1-SA are slightly lower in the range $(0.9991,1)$. The similarities in estimating carbon emissions prices using both seasonally unadjusted and seasonally adjusted data suggest that the carbon emissions prices can be calculated reasonably accurately.

As discussed in Section 3, the unit of $k$ is equal to $\mathrm{ppm} /\left\{(\mathrm{kWh})^{\mathrm{a} 3}\right\}$, and the unit of $\mathrm{P}_{\mathrm{E}}$ is equal to JPY $/ \mathrm{kWh}$. As $P_{C E}=\hat{k} P_{E}$, the unit of $\mathrm{P}_{\mathrm{CE}}$ is JPY $* \mathrm{ppm} /\left\{(\mathrm{kWh})^{(1+\mathrm{a} 3)}\right\}$. The estimates of $\mathrm{P}_{\mathrm{CE}}$ are tabulated in Figures 1-4 for seasonally unadjusted and adjusted data. The estimated monthly carbon emissions prices for Japan lie in the range $(1500,5500)$ in all cases.

This adds further support for the accuracy in estimating carbon emissions prices for Japan on the basis of both seasonally unadjusted and seasonally adjusted data. 


\section{CONCLUDING REMARKS}

There would seem to be no published theoretical or practical academic literature on pricing carbon emissions for Japan. There have been few attempts at establishing national carbon emission prices, with an exception being the recent work of Chang et al. (2019) for China.

As stated in the introductory section, it is hoped that the innovative theoretical approach and empirical results of the paper will encourage further research into pricing carbon emissions, preferably using high frequency time intervals, such as daily data, and to encourage public policy consideration.

The paper used an innovative KLEM production function approach to calculate carbon emission prices, where carbon emissions (CE) are the outputs and capital (K), labour (L), energy (E) (that is, electricity), and materials $(\mathrm{M})$, are the inputs into the production process. The variables $\mathrm{K}, \mathrm{L}$ and $\mathrm{M}$ are essentially fixed on a daily, weekly or monthly basis, whereas $\mathrm{E}$ can be changed far more frequently, such as daily, weekly or monthly, so that changes in CE essentially depend on changes in E.

The methodological approach based on the production function approach is innovative, and the empirical analysis is also novel, not only for Japan, and complements the few existing analyses of carbon emissions pricing internationally.

Under the assumption that output prices are set according to an average cost pricing rule, the prices of $\mathrm{CE}$ and E may be approximated by an energy production model with a constant factor of proportionality. In this setting, the prices of $\mathrm{CE}$ will depend on the prices of $\mathrm{E}$.

Using this innovative approach, the paper estimated carbon emissions prices for Japan using seasonally adjusted and unadjusted monthly data on the production volumes of carbon emissions and electricity, and the prices of electricity, from December 2008 to April 2018. The estimated monthly carbon emissions prices for Japan lie in the range $(1500,5500)$ in all cases considered, including seasonally adjusted and unadjusted data, and accommodating deterministic seasonal patterns in the monthly data.

The calculated carbon emissions prices are sensitive and important for public policy consideration. Prices are essential for purposes of imposing taxes on carbon emissions in order to mitigate the effect of carbon emissions on the environment, namely global warming and climate change.

The calculation of carbon emissions prices has been undertaken for only a few countries to date. The innovative methodological and novel empirical approach taken in this paper should enhance the application and analysis of carbon emissions pricing to a much wider audience. It is also a primary purpose of the paper to encourage public policy consideration at the international level. 


\section{REFERENCES}

Chang, C.-C. (2010), A Multivariate Causality Test of Carbon Dioxide Emissions, Energy Consumption and Economic Growth in China, Applied Energy, 87, 3533-3537.

Chang, C.-L., T.K. Mai and M. McAleer (2019), Establishing National Carbon Emission Prices for China, Renewable \& Sustainable Energy Reviews, 106, 1-16.

Chang, C.-L. and M. McAleer (2018), The Fiction of Full BEKK: Pricing Fossil Fuels and Carbon Emissions, Finance Research Letters, 28, 11-19.

Chang, C.-L., M. McAleer and G.D. Zuo (2017), Volatility Spillovers and Causality of Carbon Emissions, Oil and Coal Spot and Futures for the EU and USA, Sustainability, 9(10:1789), 1-21.

Chen, W. (2005), The Costs of Mitigating Carbon Emissions in China: Findings from China MARKALMACRO Modeling, Energy Policy, 33(7), 885-896.

Daskalakis G., D. Psychoyios, and R.N. Markellos (2009), Modeling CO2 Emission Allowance Prices and Derivatives: Evidence from the European Trading Scheme, Journal of Banking \& Finance, 33, 1230-1241.

Gregg, J.S., R.J. Andres, and G. Marland (2008), China: Emissions Pattern of the World Leader in CO2 Emissions from Fossil Fuel Consumption and Cement Production, Geophysical Research Letters, 35, L08806, 1-5.

Japan Electricity Power eXchange (http://www.jepx.org/market/index.html).

Japan Meteorological Agency (https://ds.data.jma.go.jp/ghg/kanshi/info_co2.html).

Lecca, P., K. Swales and K. Turner (2011), An Investigation of Issues Relating to Where Energy Should Enter the Production Function, Economic Modelling, 28(6), 2832-2841.

Li, J. and M. Colombier (2009), Managing Carbon Emissions in China Through Building Energy Efficiency, Journal of Environmental Management, 90(8), 2436-2447.

Nam, K.-M., C.J. Waugh, S. Paltsev, J.M. Reilly, and V.J. Karplus (2014), Synergy Between Pollution and Carbon Emissions Control: Comparing China and the United States, Energy Economics, 46, 186-201.

OECD (2001), OECD Productivity Manual: A Guide to the Measurement of Industry-Level and Aggregate Productivity Growth, Statistics Directorate, Directorate for Science, Technology and Industry, Paris.

Phillips, P. and Hansen, B. (1990), Statistical Inference in Instrumental Variables Regression with I(1) Processes, Review of Economic Studies, 57, 99-125.

Tang, L., J. Wu, L. Yu, and Q. Bao (2015), Carbon Emissions Trading Scheme Exploration in China: A Multiagent-based Model, Energy Policy, 81, 152-169.

Xiong, L., B. Shen, S. Qi, L. Price, and B. Ye (2017), The Allowance Mechanism of China's Carbon Trading Pilots: A Comparative Analysis with Schemes in EU and California, Applied Energy, 185, 1849-1859

Zhang, Y. (2015), Reformulating the Low-Carbon Green Growth Strategy in China, Climate Policy, 15, 4059.

Zhang, Y.-J., A.-D. Wang, and Y.-B. Da (2014), Regional Allocation of Carbon Emission Quotas in China: Evidence from the Shapley Value Method, Energy Policy, 74, 454-464. 